\title{
Defect Analysis in Microgroove Machining of Nickel-Phosphide Plating by Small Cross-Angle Microgrooving
}

\author{
Xiaobin Dong, ${ }^{1}$ Tianfeng Zhou ${ }^{D},{ }^{2}$ Siqin Pang, ${ }^{2}$ Zhiqiang Liang, ${ }^{2}$ Qian Yu, \\ Benshuai Ruan, ${ }^{1}$ and Xibin Wang ${ }^{2}$ \\ ${ }^{1}$ School of Mechanical Engineering, Beijing Institute of Technology, No. 5 Zhongguancun South Street, Haidian District, \\ Beijing 100081, China \\ ${ }^{2}$ Key Laboratory of Fundamental Science for Advanced Machining, Beijing Institute of Technology, No. 5 Zhongguancun South Street, \\ Haidian District, Beijing 100081, China
}

Correspondence should be addressed to Tianfeng Zhou; zhoutf@bit.edu.cn

Received 27 November 2017; Accepted 31 January 2018; Published 27 February 2018

Academic Editor: Haihui Ruan

Copyright (C) 2018 Xiaobin Dong et al. This is an open access article distributed under the Creative Commons Attribution License, which permits unrestricted use, distribution, and reproduction in any medium, provided the original work is properly cited.

\begin{abstract}
Crystalline nickel-phosphide (c-Ni-P) plating is a newly developed mold material for precision glass molding (PGM) to fabricate microgrooves. In the ultraprecision cutting process of the c-Ni-P plating material, the neighboring microgrooves are required to adjoin with each other to ensure acute microgroove ridges and miniaturize the microgroove size. Generally, defects of burrs and fracture pits can easily occur on the ridges when the plating layer is grooved. Burrs appear when tears dominate in material removal with a large adjacent amount. With the change of the adjacent amount, the removed material is sheared out from the workpiece, and when the cutting depth of the groove ridge is over the brittle-ductile transition thickness, fracture pits arise. To restrict these defects, a small cross-angle microgrooving method is proposed to test the critical adjacent amount range efficiently. It is found that an acute ridge of the microgroove is formed with a small enough adjacent amount; when this amount is in the range of $570 \mathrm{~nm} \sim 720 \mathrm{~nm}$ in the microgroove machining process, fracture pits begin to arise on the gradient edge. High-quality microgrooves can be obtained based on this methodology.
\end{abstract}

\section{Introduction}

An optical glass microgroove array is an important component in photoelectric systems due to its function of reducing light reflectivity, improving transmittance/diffraction efficiency, and controlling light spectrum distribution [1-3]. However, it is difficult to fabricate optical glass microgrooves directly because of the brittleness of the glass materials at room temperature [4-6]. Precision glass molding (PGM) is a promising method to fabricate glass microgroove arrays with high efficiency, high accuracy, and low cost [7-9]. The shape of the molded glass is decided by the patterns on the mold surface, and the quality of the mold is of great significance for the PGM process. The mold material should have sufficiently high hardness at molding temperature and favourable micromachinability at room temperature. Silicon carbide (SiC) and tungsten carbide (WC) are too hard to be machined, while the copper and aluminium are too soft to maintain the microshape under high pressure $[10,11]$.

Electroless nickel-phosphide (Ni-P) plating is an important mold surface preparation technology, which provides hard, wear-resistant, and corrosion-resistant surfaces with excellent micromachinability for single-point diamond cutting $[12,13]$. A two-step cutting process that eliminates burr formation along the microgroove side and improves the quality of the microgroove on Ni-P plating was proposed by Yan et al. [14]. The forming mechanism of the burr was studied based on the pile-up model in a scratch test. The cutting depth and the edge radius of the diamond tool are considered to be the two main factors of burr formation due to the plastic flow material [15]. An energy method was used to predict the chip flow directions, and the calculated results agreed with the experimental results, which proved that the energy method is valid for designing 


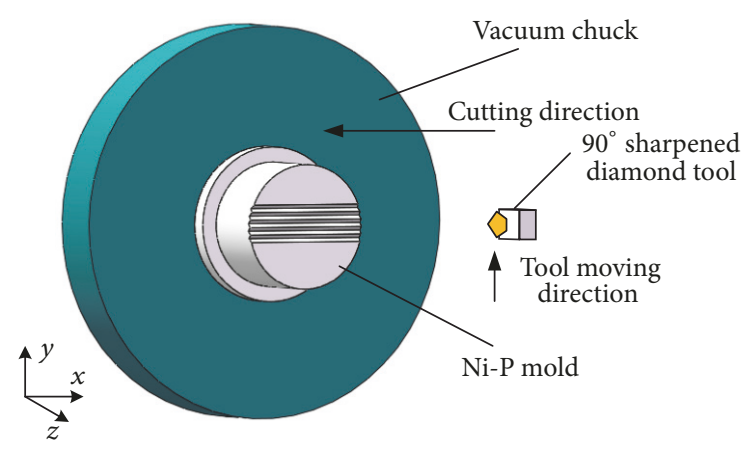

FIGURE 1: Ni-P microgroove mold single-point diamond cutting.

appropriate undeformed chip geometry to reduce burrs in ultraprecision microgrooving on Ni-P plating [16]. The wear and tear of the mold was the bottleneck of restriction of the PGM. To improve the hardness of the mold and prolong the service life, crystalline nickel-phosphide was developed by heat treatment $[17,18]$. The material characteristics and removal mechanism of crystalline Ni-P plating are quite different than those of amorphous plating in terms of both brittleness and ductility for crystalline Ni-P. Few studies have been performed on the defect reduction and high-precision microgroove machining on the crystalline Ni-P material.

The goal of this paper is to restrict the defects that emerge on the ridge of the microgroove machined on crystalline $\mathrm{Ni}-\mathrm{P}$ plating. In the microgrooving process, we denoted the overlap gap between the neighboring microgrooves "adjacent amount," which determines the size and the interval of the microgrooves. Burrs and fracture pits are easily formed on the microgroove ridge during the microgroove forming with different adjacent amounts. First, the forming mechanisms are discussed theoretically. To identify the forming mechanism of the defect and educe the appropriate adjacent amount, a method of small cross-angle microgrooving is proposed. Next, the defects of microgroove machining are identified on the gradient edge formed by the method. Finally, through the gradual change of the material removal condition, the microgroove machining mechanism for different adjacent amounts is analysed.

\section{Difficulties of Ni-P Mold Microgrooving}

2.1. Mold Microgrooving Process. The experiment of microgroove machining is carried out on an ultraprecision machine centre Nanoform X (produced by Precitech Corporation, USA), which achieves a positioning resolution of $0.016 \mathrm{~nm}$ and a moving straightness of $0.1 \mu \mathrm{m} / 50 \mathrm{~mm}$. As shown in Figure 1, the workpiece of the Ni-P mold that is fixed by a vacuum chunk is machined by a $\mathrm{V}$-shaped diamond tool with an included angle of $90^{\circ}$.

A precision vertical positioning stage fixed under the tool holder is developed to achieve height adjustment. The diamond tool should find the surface of the mold before the machining, and a tool setting error is inevitable in this step, regardless of the precision of the machine tool. For this problem, the neighboring grooves must be adjoining

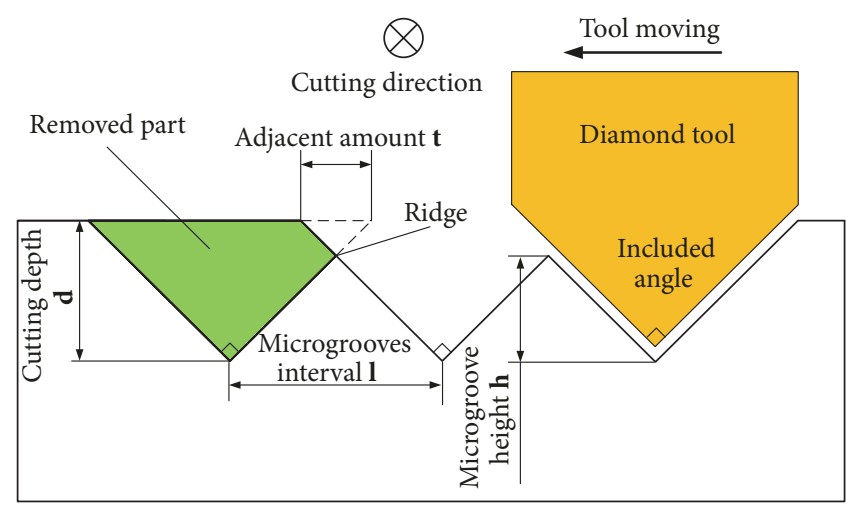

FIGURE 2: Diagram of adjacent amount control for microgrooves.

with each other to a certain extent to ensure high-precision machining and an acute microgroove ridge. In this way, the size of the microgroove is determined by the interval of neighboring grooves $l$ instead of cutting depth $d$ (Figure 2). Thus, the tool setting error is totally eliminated. The height of the microgroove is half of the interval of neighboring grooves for the cutting tool of the $90^{\circ}$ included angle. The adjacent amount $t$ is obtained:

$$
t=2 d \tan 45^{\circ}-l .
$$

2.2. Machining Defects in Mold Microgrooving. Figure 3 shows scanning electron microscope (SEM) images of defects, including burrs and fracture pits. During cutting, the tool moved from right to left, and the feed of each single microgroove cutting is $3.0 \mu \mathrm{m}$. The intervals of the microgrooves are $1.0 \mu \mathrm{m}$ and $4.8 \mu \mathrm{m}$. It can be deduced from (1) that the adjacent amounts are $5.0 \mu \mathrm{m}$ and $1.2 \mu \mathrm{m}$, respectively. In Figure 3(a), burrs are formed on the side of an earlier machined microgroove. The morphology of the burrs shows that the cutting direction is from the bottom up. In Figure 3(b), discontinuous fracture pits are located mainly on the ridges of the later machined surface of each single microgroove.

\section{Mechanism of Defect Formation in Microgrooving}

3.1. Modelling of Defect Formation in Microgrooving. Burr restricting is important in microgroove machining. Gillespie was among the first to describe different types of burrs. Four types of machining burrs were defined (Figure 4): Poisson burr, rollover burr, tear burr, and cut-off burr. The Poisson burr results from the material's tendency to bulge to the sides when it is compressed until permanent plastic deformation occurs. The forming mechanism of a rollover burr is essentially the material being bent in a cutting process such as end milling. The tear burr is the result of material tearing loose from the workpiece rather than shearing clearly. The cut-off burr is the result of workpiece separation from the raw material before the separation cut is finished $[19,20]$. The size of the burrs in the SEM photo is similar to the height of the microgroove, which is too large to form by extrusion or 


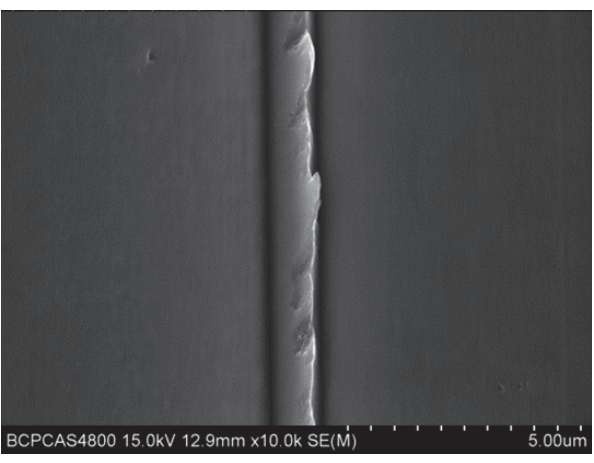

(a)

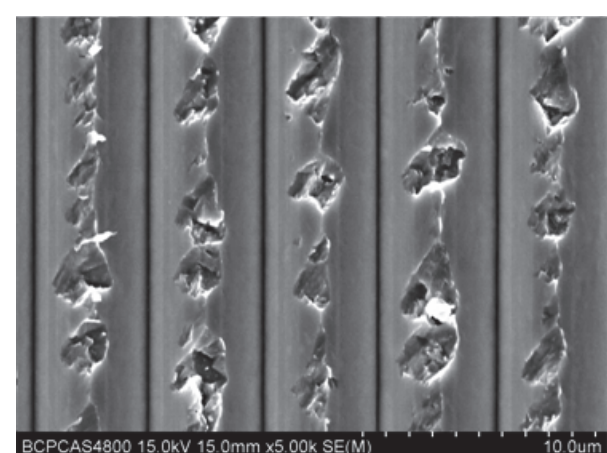

(b)

Figure 3: Machining defects of adjacent microgrooves: (a) burrs and (b) fracture pits.

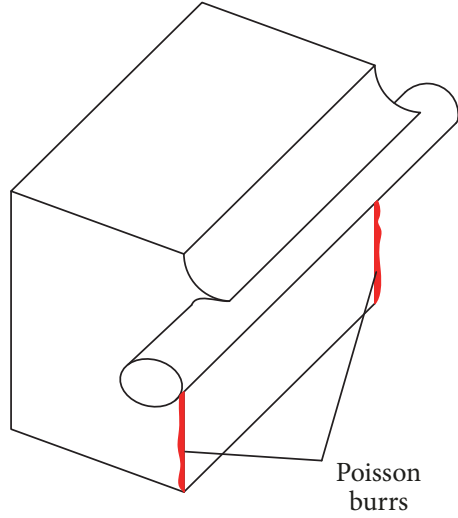

(a)

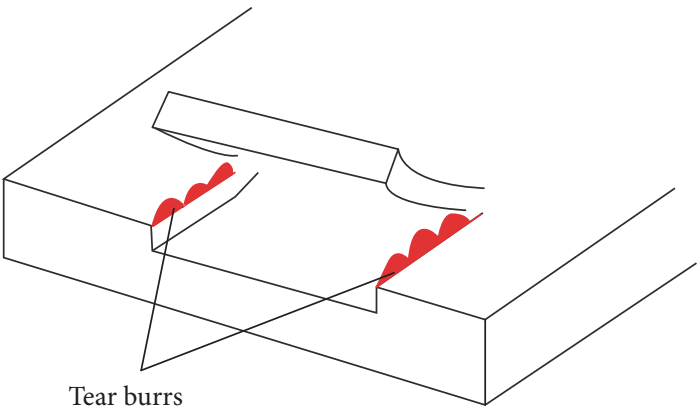

(c)

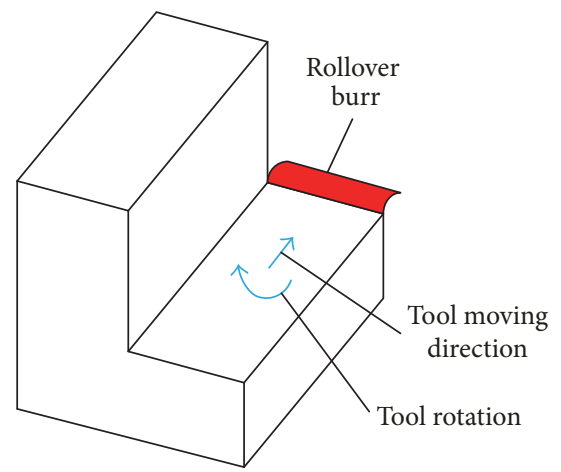

(b)

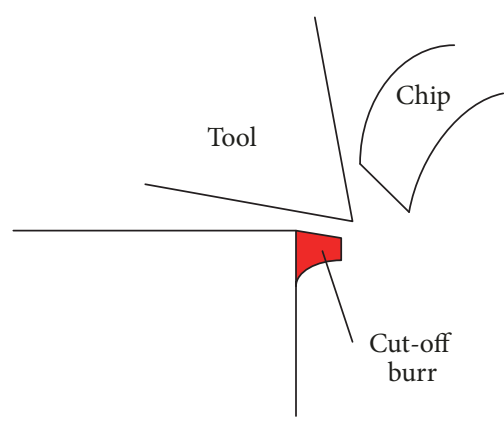

(d)

FIgURE 4: Schematic of machining burrs: (a) Poisson burr, (b) rollover burr, (c) tear burr, and (d) cut-off burr.

shearing, and it is obvious that the burrs are not formed by material bent for their shape. Therefore, the burr is speculated to be a typical kind of tear burr.

As the chip flow state is one of the important factors of the burr formation mechanism, plastic deformation in the adjacent microgrooving process should be considered. The workpiece material is pressed by the cutting tool, while the friction between the tool and material is ignored. Under these circumstances, the minimum resistance principle can be used to estimate the flow of the material macroscopically in plastic deformation. According to this principle, in the compression process, the particle of the plastic deformation material always flows along the direction with the least resistance, which is the shortest normal of the object contour (Figure 5).

Different kinds of defects are formed according to the adjacent amount of microgrooves. Burrs are formed on the groove ridge with a large adjacent amount, while fracture pits occur with a small adjacent amount. The material flow condition is analysed by the minimum resistance principle, and the chip flow direction is estimated (Figure 6). According to the minimum resistance law, the section of the removed material is divided into four parts; the material flows of Part II and Part III are blocked by the workpiece material. Therefore, 


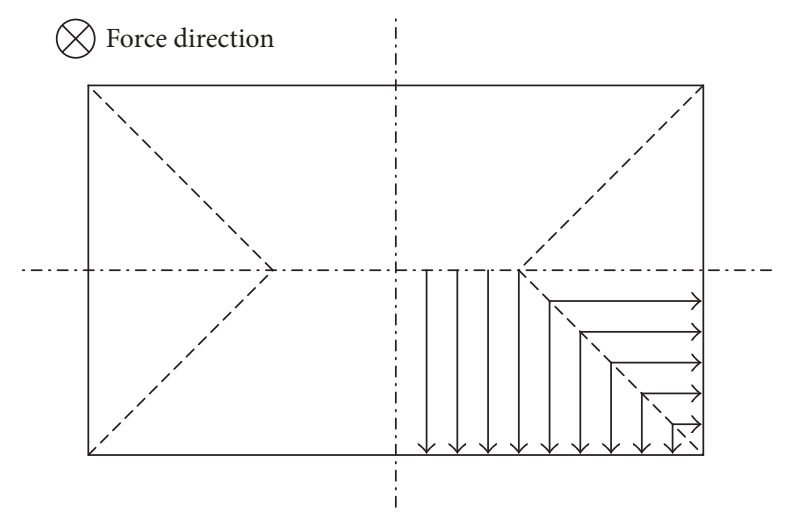

FIGURE 5: Diagram of minimum resistance principle.

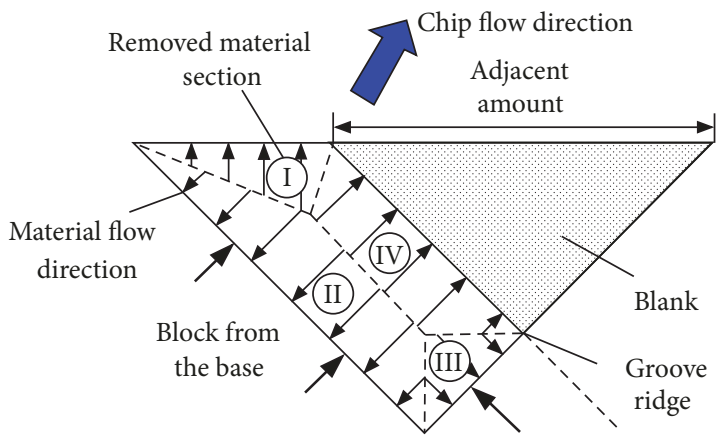

(a)

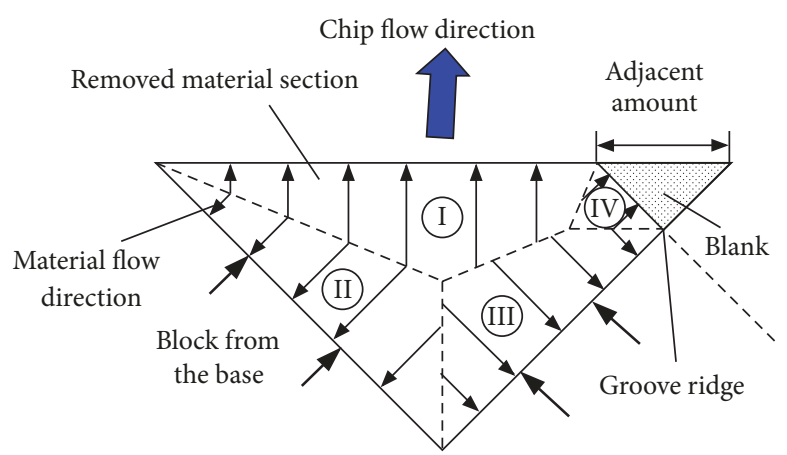

(b)

FIGURE 6: Material flow in the microgrooving under different conditions: (a) large adjacent amount and (b) small adjacent amount.

the chip flow direction is affected by the combination of material flow from Part I and Part IV. The estimated chip flow directions are shown. For the chip flow condition in Figure 6(a), the material near the groove ridge tends to be torn out from the workpiece. In this situation, tearing dominates the material removal process.

As seen in Figure 6(b), the cutting depth at the position of groove ridge is directly proportional to the adjacent amount. For the crystalline Ni-P material, fracture pits are observed on the groove ridge, and the brittle removal process is illustrated in Figure 7. The crack begins to appear when the cutting depth reaches the brittle-ductile transition thickness. With the movement of the cutting tool, the crack propagates, and brittle exfoliation of the material occurs on the surface. In this process, one single fracture pit is formed. For the gradual change of the pit depth, the cutting thickness decreases when the cutting edge of the tool reaches the brim of the fracture pit. In this situation, the material of this part would be removed in the ductile mode. As the cutting continues, the cutting tool recedes from the fracture pit, and the cutting depth returns to the original value. Afterwards, a new cycle of brittle removal begins. The morphology of discontinuous fracture pits forms in this process.

3.2. Analysis of Defect Formation by Small Cross-Angle Microgrooving Method. The adjacent amount is considered to be the most important factor that decides the quality of the groove ridge according to the aforementioned research. The small cross-angle microgrooving method is proposed to analyse the forming mechanism of the groove ridge for different adjacent amounts. The procedure of the method is shown in Figure 8. After the machining of a microgroove, the workpiece is rotated with a small certain angle by the $C$-axis of the ultraprecision machine, and then the second microgroove that intersected with the first one is machined. A pair of gradient edges is generated by the intersection of the microgrooves.

Figure 9 shows the profile of the removed part of the second cutting, and the sections of the removed part at different positions of the gradient edge are marked. It can be observed that the shapes of the sections are similar to the removed part section of the parallel microgroove machined with an adjacent amount. Each section along the gradient edge could be matched with corresponding parallel microgroove machining sections shaped with different adjacent amounts. To confirm this result, the angles of the gradient edges formed by different cross angles of microgrooves in small cross-angle microgrooving experiments are calculated and shown in Table 1 . The edge angle $\theta$ becomes larger as the microgroove cross-angle $\alpha$ increases. When the cross angle is in the range of $0^{\circ} \sim 10^{\circ}$, the edge angle varies within $0.5^{\circ}$, which is sufficiently small to be ignored. The change of the cross 


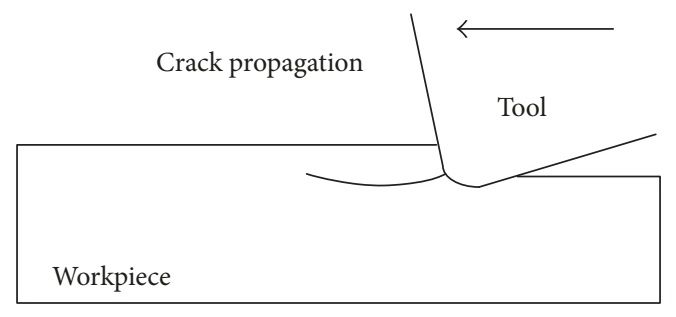

(a)

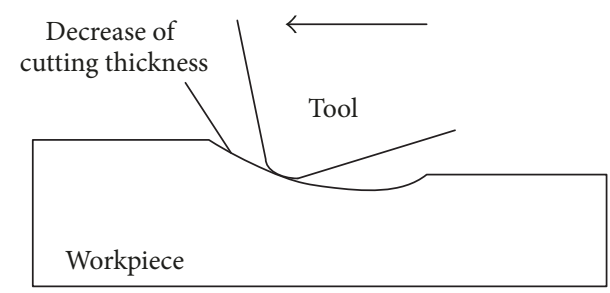

(c)

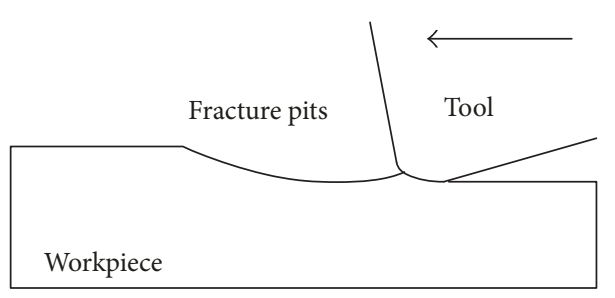

(b)

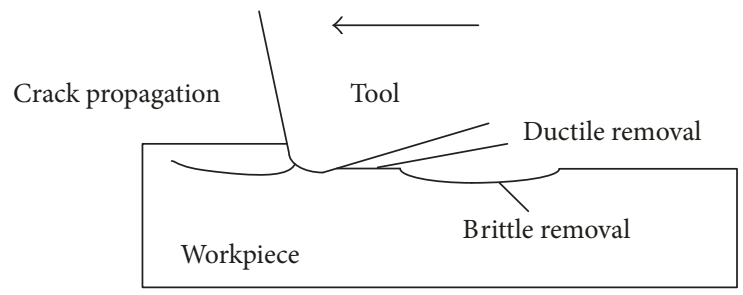

(d)

FiguRE 7: Material removing process of the crystalline Ni-P: (a) crack propagation, (b) brittle exfoliation, (c) ductile machining, and (d) formation of next fracture pit.

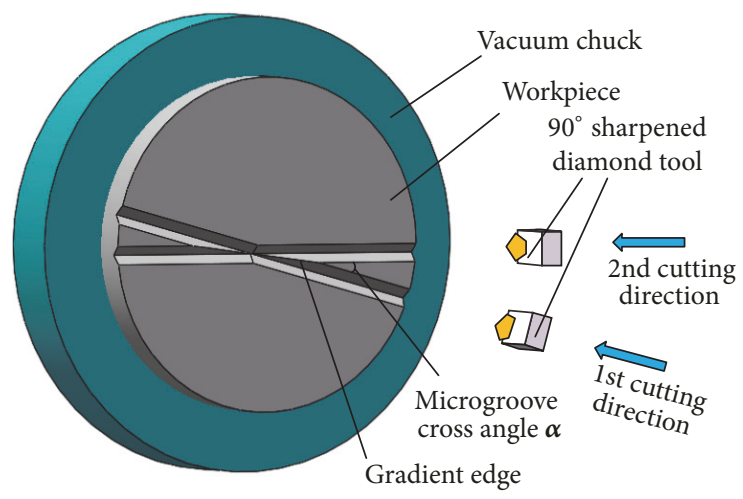

FIGURE 8: Experimental setup of small cross-angle microgrooving.

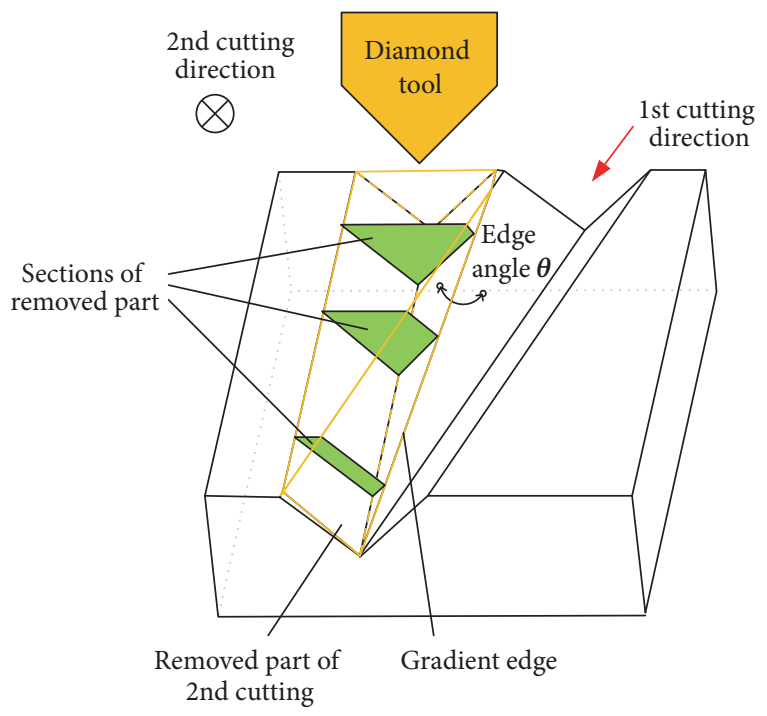

FIGURE 9: Sections of the removed material of the 2nd cutting.
TABLE 1: Relationship between cross angle and gradient edge angle.

\begin{tabular}{lc}
\hline Microgroove cross-angle $\alpha\left(^{\circ}\right)$ & Edge angle $\theta\left(^{\circ}\right)$ \\
\hline 2 & 90.01745 \\
5 & 90.10901 \\
8 & 90.27880 \\
10 & 90.43523 \\
\hline
\end{tabular}

angle in this range has little effect on the shape of the removed section. The shape of the section could be considered to be the same as that of parallel microgroove machining.

The gradient edge formed in the small cross-angle microgrooving experiment is shown in Figure 10. Burrs and fracture pits are observed on the gradient edge, and there is no defect at the upper part of the gradient edge. The burrs are formed on the side of the first cutting direction. The fracture pits are discontinuous and mainly formed on the side of the second microgroove. At this point, the cutting depth at the position of groove ridge is less than the brittle-ductile transition thickness, and the material is removed in the ductile mode. The above signs show that the material removal mechanism in small cross-angle microgrooving experiments is the same as that of adjacent parallel microgroove machining with different adjacent amounts. Thus, it is reasonable to identify the defect formation mechanism in adjacent microgroove cutting processes through small cross-angle microgrooving experiments.

\section{Defect Restriction by Controlling the Adjacent Amount}

4.1. Influences of Microgrooving Parameters. To conduct a further study of the defect forming situation, a series of small cross-angle microgrooving experiments are carried out, and the experiment parameters are summarized in Table 2. 
TABLE 2: Experiment parameters of small cross-angle microgrooving.

\begin{tabular}{lccc}
\hline Cutting speed $v(\mathrm{~mm} / \mathrm{min})$ & Depth of the 1st cutting $d_{1}(\mu \mathrm{m})$ & Depth of the 2nd cutting $d_{2}(\mu \mathrm{m})$ & Cross angle of microgrooves $\alpha\left({ }^{\circ}\right)$ \\
\hline 2400 & 3.0 & $3.0,1.5$ & $2,5,8,10$ \\
\hline
\end{tabular}

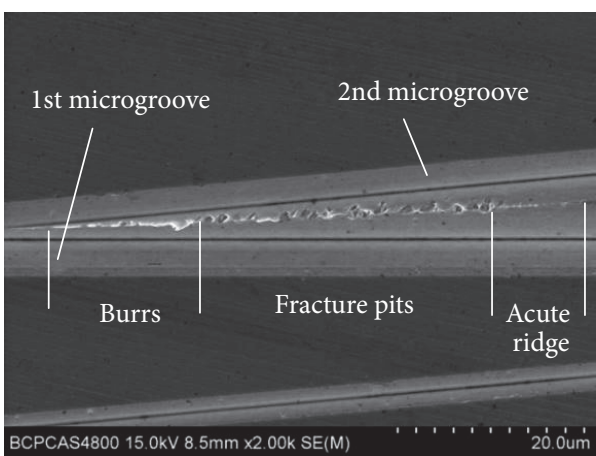

(a)

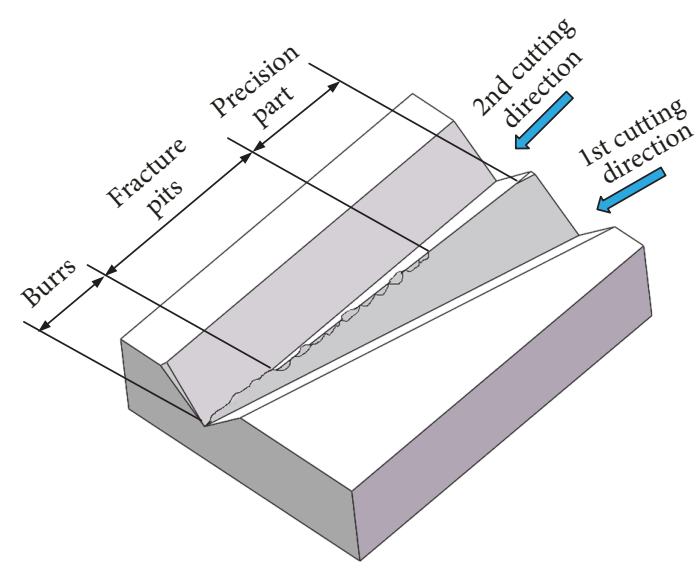

(b)

FIGURE 10: Gradient edge: (a) SEM photo and (b) overall schematic.

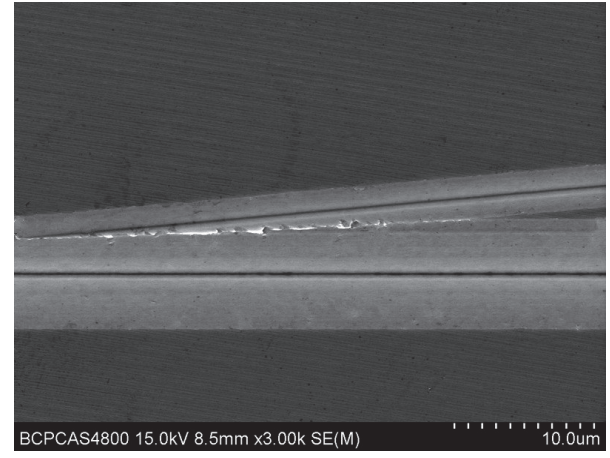

FIGURE 11: SEM photograph of gradient edge machined by cross of $1.5 \mu \mathrm{m}$ microgroove.

Several pairs of gradient edges are obtained and analysed. Gradient edges with larger sizes are created by the cross of microgrooves with larger cutting depths, while a smaller cross angle of the microgrooves makes the gradient edge slower with a certain height. Figure 11 shows a gradient edge machined by a $5^{\circ}$ cross angle of microgrooves with a cutting depth of $1.5 \mu \mathrm{m}$. Burrs are clearly observed on the formed gradient edge, while fracture pits formation is not as evident as the example shown in Figure 10(a), whose size is larger. On one hand, it could be concluded that the formation of fracture pits, which is relevant to the brittle-ductile transition thickness of the material, is closely related to the cutting depth of the microgrooves. On the other hand, since the formation of the tear burr is related to the section of the removed material part, whether it would arise or not is not affected by the cutting depth of the microgroove. Figure 12 shows a gradient edge formed by microgrooves with a $2^{\circ}$ cross angle. In this condition, the gradient edge is slower, and the defects

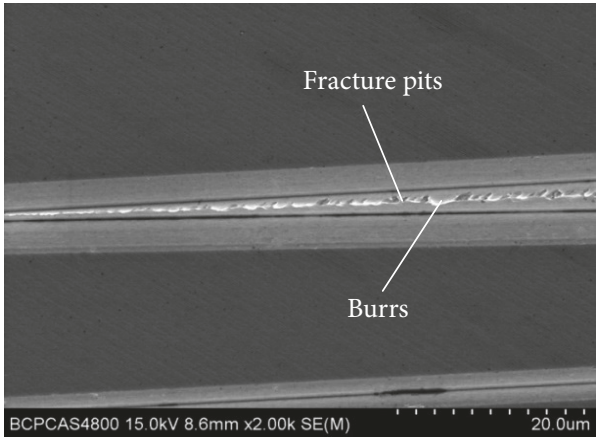

FIGURE 12: SEM photograph of mix exists of burrs and fracture pits.

could be observed clearly in a sparse distribution. As seen in the figure, burrs and fracture pits coexist on the middle part of the gradient edge, which indicates that the forming mechanisms of these two defects are independent and have no effect on each other.

The high-quality part on the gradient edge corresponds to the acute ridge machined in the parallel microgrooving process. In theory, the high-quality parts of exit and entrance gradient edges should be the same length based on the previous research of the removed material section. However, it can be observed from the SEM photographs that the range of the high-quality region on the exit gradient edge is wider than that of the entrance gradient edge. In addition, the size of the fracture pits on the entrance gradient edge is larger (Figure 13). To summarize, the brittle-ductile transition occurs in a smaller adjacent amount on the exit gradient edge than the entrance gradient edge, and the phenomenon of brittle exfoliation is more remarkable on the entrance gradient edge. 


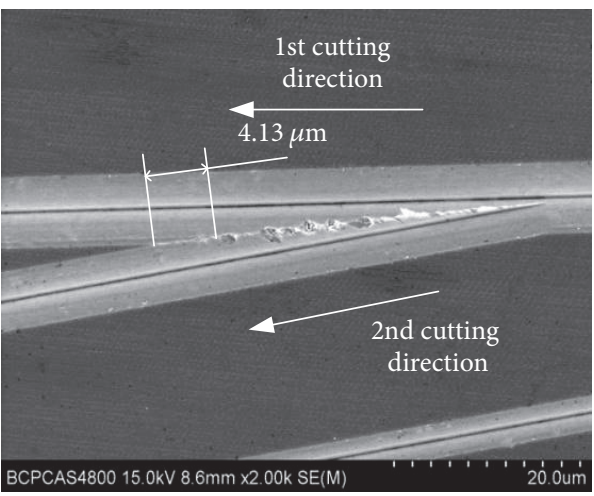

(a)

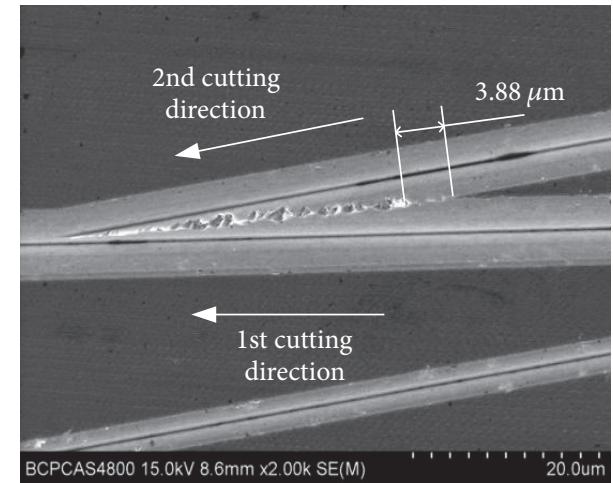

(b)

FIGURE 13: SEM photographs of: (a) exit gradient edge and (b) entrance gradient edge.

The removed material thickness on the edge increases with the diamond tool moving during the entrance gradient edge machining process. On one hand, the tensile stress between the chip and the undeformed surface material makes fracture pits easier to form on the brittle material. On the other hand, for the machining process of the exit part, the crack propagation and brittle exfoliation of the material on the edge are restrained by the hydrostatic pressure from the cutting tool. This explains why the quality of the exit gradient edge is better than that of the entrance, and the edge quality of adjacent microgrooves goes between them. For these reasons, the brittle-ductile transition positions of the exit and entrance gradient edges are, respectively, set as the upper and lower bounds for the brittle-ductile adjacent amount of microgroove machining.

\subsection{Optimization and High-Quality Machining of Micro-} grooves. The corresponding adjacent amount of the position on the gradient edge could be obtained by geometric calculation, and the various brittle-ductile transition adjacent amounts achieved in the cross-cutting process under different cross angles are shown in Figure 14. The values of the adjacent amounts machined by different microgroove cross-angle degrees tend to be quite close, with no gradual change trend. Thus, the conclusion could be drawn that, under the test condition, the tiny change of the gradient edge shape has little effect on the brittle-ductile transition adjacent amount of the gradient edge, and the testing method is feasible. According to this method, when the adjacent amount is in the range of $570 \mathrm{~nm} \sim 720 \mathrm{~nm}$, the fracture pits begin to occur on the gradient edge, which is considered to be the transitional adjacent amount of the microgroove cut.

The defects of the machined microgroove array are difficult to repair due to the relocation difficulty of the tool and the workpiece in the machining process. Errors in submicron scale for the relative coordinate system of the workpiece surface established by tool setting, which would reflect the cutting depth, are unacceptable in ultraprecision machining. The actual cutting depth is the sum of the tool setting amount and the cutting feed, which is not an accurate value due to the uncertainty in the tool setting process. Therefore, estimations

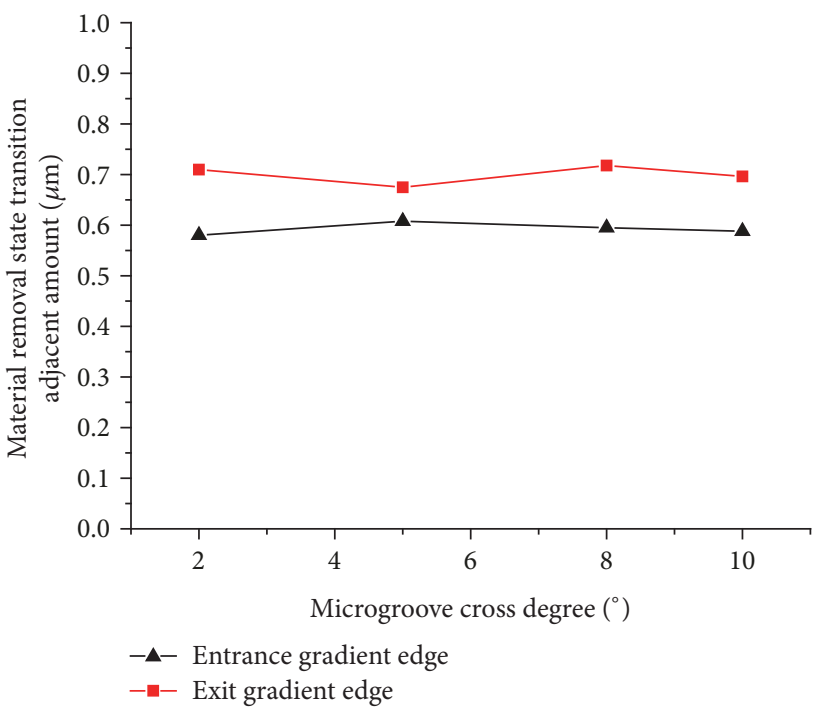

FIGURE 14: Effect of cross angle on transition adjacent amount in the material removal.

must be made to assure the high precision of the microgroove, and the prediction of the brittle-ductile transition adjacent amount provides guidance to the machining process. The cutting feed and interval of the microgrooves are rationally designed according to the tool setting conditions and depth of the microgrooves. The microgroove machining can be carried out in the appropriate adjacent amount where the material is removed in a ductile manner, and a microgroove mold with a high-quality ridge is obtained (Figure 15).

\section{Conclusion}

A new method to quickly estimate the appropriate adjacent amount range in a c-Ni-P mold microgrooving process is proposed. The theoretical model is established, and the brittle-ductile transition adjacent amount range of crystalline $\mathrm{Ni}-\mathrm{P}$ plating is investigated for the optimization of the cutting conditions in a microgroove mold machining process. The main conclusions are as follows: 


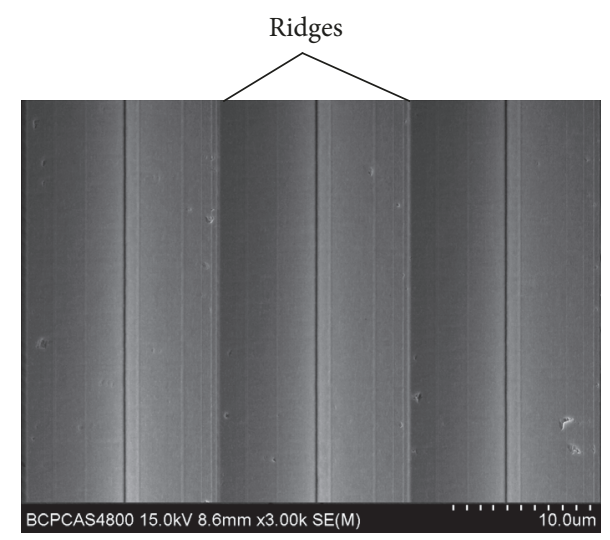

FIGURE 15: High-quality microgrooves with acute ridges.

(1) Two types of defects, namely, burrs and fracture pits, are found to coexist in the ultraprecision cutting of a Ni$\mathrm{P}$ microgroove mold subjected to the adjacent amount of microgrooves.

(2) Small cross-angle microgrooving is an effective method to test the brittle-ductile transition region. The material removal and deformation mechanism on the gradient edge resemble that of microgrooves machining in different adjacent amounts.

(3) Generally, the quality on the exit gradient edge is superior to that on the entrance counterpart, and the ridge edge quality of adjacent microgrooves falls between them in the similar removed material section.

(4) For the crystalline Ni-P plating mold, the defects of burrs and fracture pits on the microgroove ridge can be effectively restrained when the microgroove adjacent amount is less than $570 \mathrm{~nm}$.

\section{Conflicts of Interest}

The authors declare that they have no conflicts of interest.

\section{Acknowledgments}

This work has been financed by the National Key Basic Research Program of China (no. 2015CB059900) and the National Natural Science Foundation of China (no. 51375050). The authors would also like to acknowledge the support from the Fok Ying-Tong Education Foundation for Young Teachers in the Higher Education Institutions of China (no. 151052).

\section{References}

[1] B. Guo, Q. Zhao, and X. Fang, "Precision grinding of optical glass with laser micro-structured coarse-grained diamond wheels," Journal of Materials Processing Technology, vol. 214, no. 5, pp. 1045-1051, 2014.

[2] P. Li, J. Xie, J. Cheng, and Y. N. Jiang, "Study on weak-light photovoltaic characteristics of solar cell with a microgroove lens array on glass substrate," Optics Express, vol. 23, no. 7, pp. A192A203, 2015.
[3] K. Naessens, A. Van Hove, T. Coosemans et al., "Fabrication of microgrooves with excimer laser ablation techniques for plastic optical fibre array alignment purposes," in Proceedings of the Laser Applications in Microelectronic and Optoelectronic Manufacturing V, pp. 309-315, January 2000.

[4] L. J. Yang, Y. Wang, Z. G. Tian, and N. Cai, "YAG laser cutting soda-lime glass with controlled fracture and volumetric heat absorption," The International Journal of Machine Tools and Manufacture, vol. 50, no. 10, pp. 849-859, 2010.

[5] J. Shinozuka and Y. Imakama, "Effect of parallel micro-grooves fabricated on the rake and flank faces on the improvement of the cutting performance of low-rigidity elastomers," Seimitsu Kogaku Kaishi/Journal of the Japan Society for Precision Engineering, vol. 83, no. 7, pp. 679-686, 2017.

[6] D. J. Stephenson, X. Sun, and C. Zervos, "A study on ELID ultra precision grinding of optical glass with acoustic emission," The International Journal of Machine Tools and Manufacture, vol. 46, no. 10, pp. 1053-1063, 2006.

[7] T. Zhou, J. Yan, J. Masuda, and T. Kuriyagawa, "Investigation on the viscoelasticity of optical glass in ultraprecision lens molding process," Journal of Materials Processing Technology, vol. 209, no. 9, pp. 4484-4489, 2009.

[8] T. Zhou, J. Yan, J. Masuda, T. Oowada, and T. Kuriyagawa, "Investigation on shape transferability in ultraprecision glass molding press for microgrooves," Precision Engineering, vol. 35, no. 2, pp. 214-220, 2011.

[9] T. Zhou, J. Yan, and T. Kuriyagawa, "Size effects on transferability and mold change of glass molding press for microgrooves," Advanced Materials Research, vol. 497, pp. 235-239, 2012.

[10] N. Al-Aqeeli, N. Saheb, T. Laoui, and K. Mohammad, "The synthesis of nanostructured WC-based hardmetals using mechanical alloying and their direct consolidation," Journal of Nanomaterials, vol. 2014, Article ID 640750, 16 pages, 2014.

[11] S. Ji, L. Liu, J. Zhao, and C. Sun, "Finite element analysis and simulation about microgrinding of SiC," Journal of Nanomaterials, vol. 2015, Article ID 575398, 2015.

[12] T. Zhou, J. Yan, Z. Liang, X. Wang, R. Kobayashi, and T. Kuriyagawa, "Development of polycrystalline Ni-P mold by heat treatment for glass microgroove forming," Precision Engineering, vol. 39, pp. 25-30, 2015.

[13] H. Mekaru, C. Okuyama, T. Tsuchida et al., "Development of Ni-P-plated inconel alloy mold for imprinting on pyrex glass," Japanese Journal of Applied Physics, vol. 48, no. 6, pp. 06FH0610, 2009.

[14] J. Yan, T. Oowada, T. Zhou, and T. Kuriyagawa, "Precision machining of microstructures on electroless-plated NiP surface for molding glass components," Journal of Materials Processing Technology, vol. 209, no. 10, pp. 4802-4808, 2009.

[15] X. Liu, T. Zhou, S. Pang, J. Xie, and X. Wang, "Burr formation mechanism of ultraprecision cutting for microgrooves on nickel phosphide in consideration of the diamond tool edge radius," The International Journal of Advanced Manufacturing Technology, pp. 1-7, 2017.

[16] R. Kobayashi, S. Xu, K. Shimada, M. Mizutani, and T. Kuriyagawa, "Defining the effects of cutting parameters on burr formation and minimization in ultra-precision grooving of amorphous alloy," Precision Engineering, vol. 49, pp. 115-121, 2017.

[17] Y. Liu, W. Zhao, T. Zhou, X. Liu, and X. Wang, "Microgroove machining on crystalline nickel phosphide plating by singlepoint diamond cutting," The International Journal of Advanced Manufacturing Technology, vol. 91, no. 1-4, pp. 477-484, 2017. 
[18] Y. Liu, W. Zhao, T. Zhou, X. Liu, and X. Wang, "Surface defect elimination in microgrooving of electroless nickel phosphide plating layer by brittleness enhancement," The International Journal of Advanced Manufacturing Technology, pp. 1-7, 2017.

[19] J. C. Venter, K. Remington, J. F. Heidelberg et al., "Environmental genome shotgun sequencing of the sargasso sea," Science, vol. 304, no. 5667, pp. 66-74, 2004.

[20] J. C. Aurich, D. Dornfeld, P. J. Arrazola, V. Franke, L. Leitz, and S. Min, "Burrs-Analysis, control and removal," CIRP Annals Manufacturing Technology, vol. 58, no. 2, pp. 519-542, 2009. 


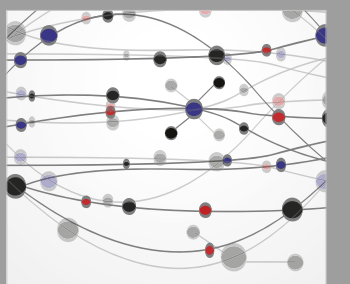

The Scientific World Journal
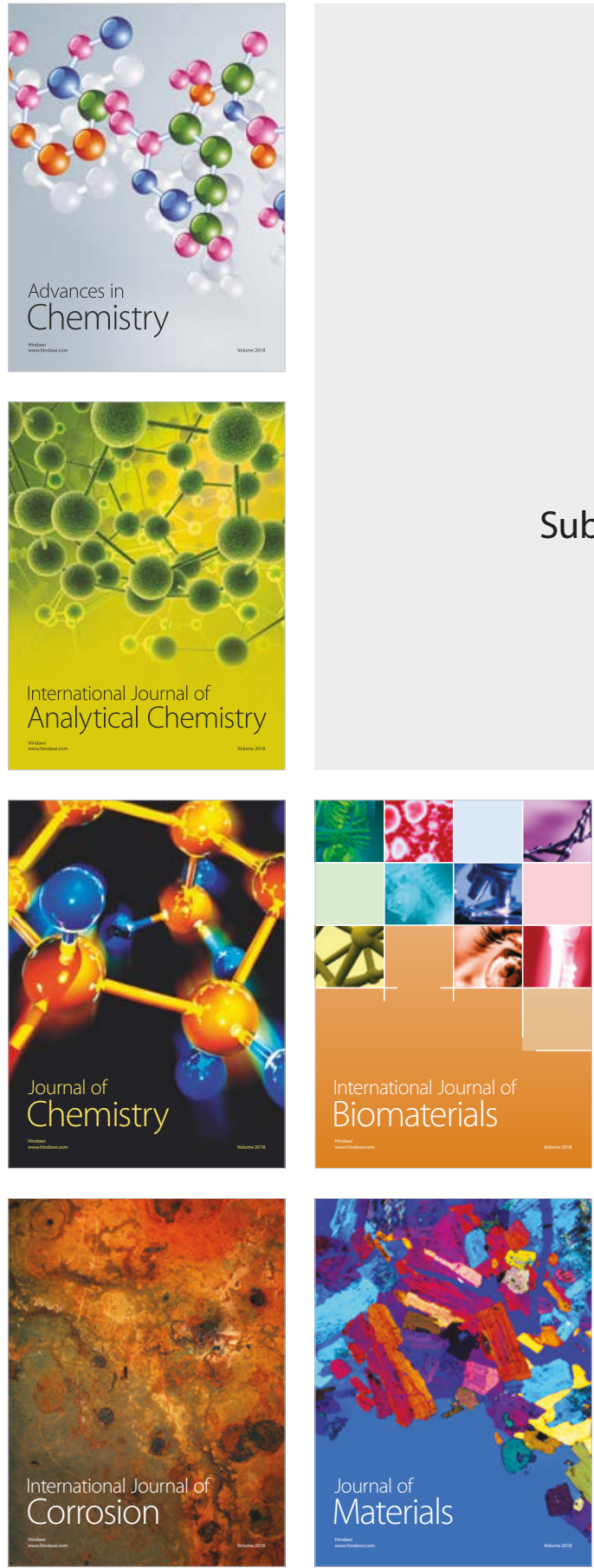

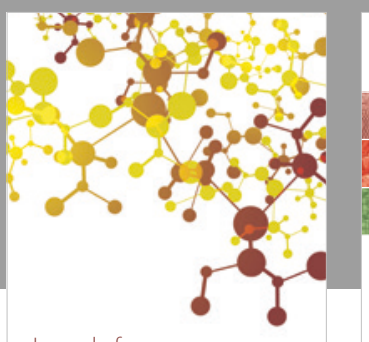

Journal of

Applied Chemistry
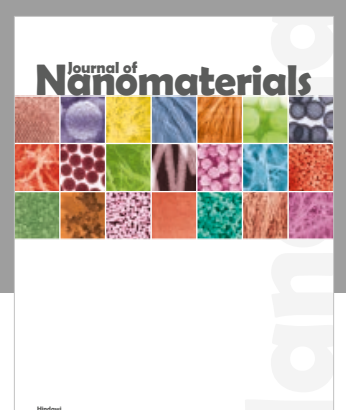

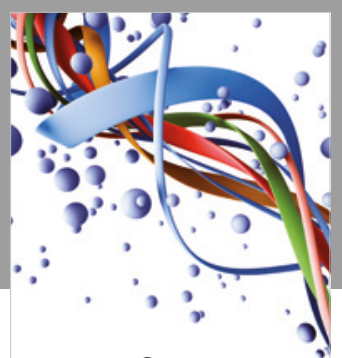

Scientifica

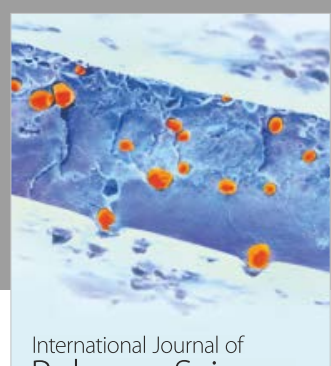

Polymer Science

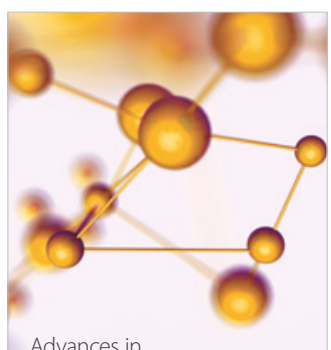

Physical Chemistry
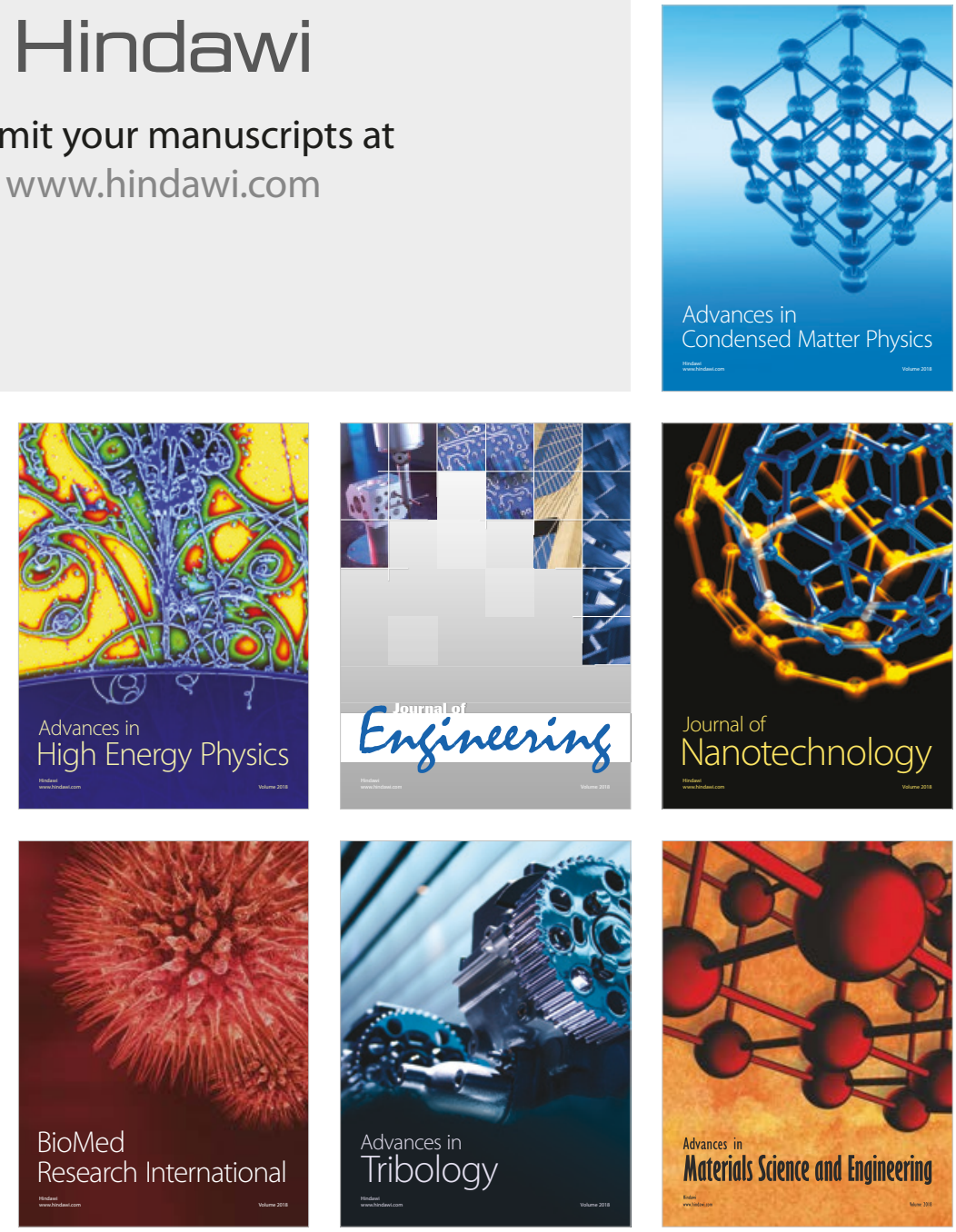